\title{
Global trends in pancreas cancer among Asia-Pacific population
}

\author{
Rohit Ranganath, Quyen Chu
}

Department of Surgery, Louisiana State University Health Sciences Center, Shreveport, LA, USA

Contributions: (I) Conception and design: All authors; (II) Administrative support: All authors; (III) Provision of study materials or patients: All authors; (IV) Collection and assembly of data: All authors; (V) Data analysis and interpretation: All authors; (VI) Manuscript writing: All authors; (VII) Final approval of manuscript: All authors.

Correspondence to: Rohit Ranganath, MD. Department of Surgery, Louisiana State University Health Sciences Center, 1501 Kings Hwy, Shreveport, LA, USA. Email: rranga@1suhsc.edu.

\begin{abstract}
The incidence of pancreatic cancer is rising. Understanding trends of pancreatic cancer is crucial prior to putting policies and interventions in place. Countries with a high human development index (HDI) have a higher incidence, prevalence and mortality due to pancreatic cancer. This global trend is replicated in the Asia-Pacific countries with high HDI having higher incidence, prevalence and mortality due to pancreatic cancer. The incidence of pancreatic cancer is rising in the Asia-Pacific population as life expectancy increases with a rising HDI. Lack of good cancer registries has resulted in under reporting of pancreatic cancer in developing countries in the Asia-Pacific region. The mortality still remains high as in the Western world as most pancreatic cancers are diagnosed in an advanced stage of the disease due to non-availability of costeffective screening tools with few patients receiving definitive care. Smoking, alcohol consumption, poor diet and obesity are significant modifiable risk factors contributing to the development of pancreatic cancer. Population based screening for pancreatic cancer is not cost-effective. Identification of hereditary and genetic factors in the Asia-Pacific population can help in targeted screening of high-risk individuals. Policies and interventions aimed at primary prevention have the greatest potential to be cost-effective yet impactful and reduce the disease burden.
\end{abstract}

Keywords: Pancreatic cancer; Asia-Pacific population; population trends pancreatic cancer; risk factors pancreatic cancer; health policy; intervention

Submitted Feb 19, 2020. Accepted for publication Aug 26, 2020.

doi: $10.21037 /$ jgo-20-118

View this article at: http://dx.doi.org/10.21037/jgo-20-118

\section{Introduction}

Understanding epidemiological trends is crucial in combating a global scourge as pancreatic cancer. Among cancers of various organ systems, pancreatic cancer is extremely aggressive with more than 400,000 new cases globally that are diagnosed every year with almost an equal number of deaths annually. Global trends of incidence and mortality due to pancreatic cancer is higher in developed economies with a high human development index (HDI $>0.8$ ) than those in developing economies with a low HDI (HDI <0.5) (1). People in countries with higher HDI have better life expectancy; pancreatic cancer being more common in the older age group, incidence of pancreatic cancer is higher in countries with high HDI as shown by Wong et al. (2) (Figure 1). Over the last two decades there has been a substantial reduction in poverty, changes in life-style, improved healthcare literacy in Asian countries leading to improving life expectancy (3). Reporting of health care data has improved as well. Pancreatic cancer has seen a rise in incidence, with $46 \%$ of new cases coming from Asia and Australia.

Majority of the pancreatic cancers are adenocarcinomas, with less than $10 \%$ being neuroendocrine tumors (4). Most patients with pancreatic adenocarcinomas present with advanced stage due to paucity or non-specificity of symptoms (5). Cure is possible with definitive surgery 
Human development index vs. incidence-ASR(W), pancreas, in 2018, both sexes, all ages
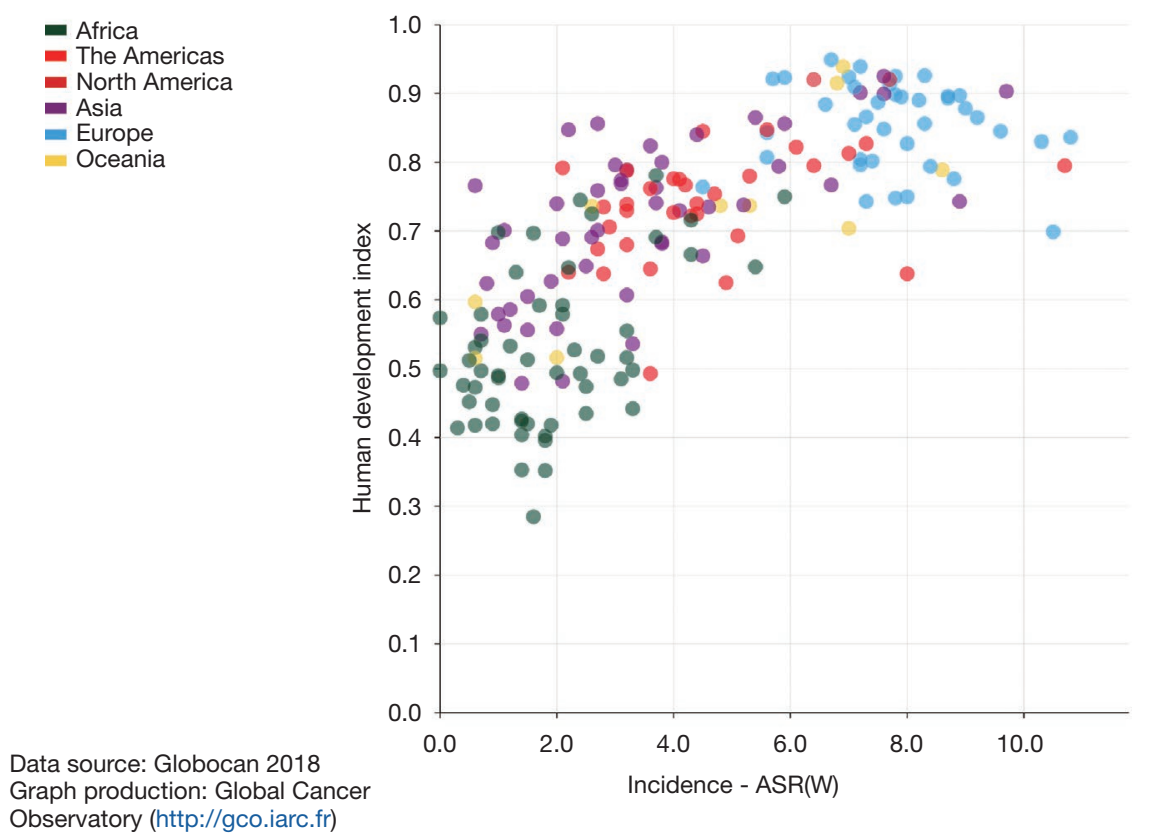
Observatory (http://gco.iarc.fr)

Figure 1 Comparing human development index (HDI) and incidence of pancreatic cancer worldwide.

though it may not be an option for the majority of patients who generally present with advanced disease. Consequently, the observed mortality associated with pancreatic cancer is high $(6,7)$.

\section{Methods}

We performed a comprehensive search in PubMed and Google Scholar from January 2000 to October 2019, restricting articles that are published in the English language.

The keywords were incidence and mortality of pancreatic cancer, epidemiology of pancreatic cancer and risk factors for pancreatic cancer. Papers and bibliography were cross-referenced to include Asia-Pacific population. GLOBOCAN March 2019 data was used as the primary database for trends in pancreatic cancer globally and in the Asia-Pacific region.

\section{Scope of the problem in Asia-Pacific population}

Based on the data published in GLOBOCAN 2019, Western Europe by far has the highest age standardized incidence $(8.3 / 100,000)$ of pancreatic cancer followed by
North America (7.6/100,000). East Asia, Australia and New Zealand which have comparable HDI, have an age standardized incidence of 5.9/100,000 and 6.9/100,000, respectively. Western Asia has a rate of 4.9/100,000. Countries in Asia with low HDI like Papua New Guinea, Nepal and Pakistan have a lower age standardized incidence of pancreatic cancer compared to those with high HDI; as a region Southeast Asia has an incidence of 2.1/100,000 while South Central Asia has 1.1/100,000 (Figure 1). The incidence of pancreatic cancer is higher in countries with a higher HDI like Japan, Singapore, South Korea and China (3) (Table 1).

The age standardized mortality rates follow a similar trend. Western Europe has a high mortality rate of 7.6/100,000, followed by North America at 6.5/100,000. East Asia and Australia have mortality rates of 5.4/100,000 and 5.9/100,000, respectively. Western Asia has a mortality rate of $4.8 / 100,000$, which is higher than the world average mortality rate at 4.4/100,000. Southeast Asia has a mortality rate of 2.1/100,000, while South Central Asia has the lowest mortality rate at 1/100,000 (Figure 2). The mortality due to pancreatic cancer is higher in countries with higher HDI (3).

Pancreatic cancer has a higher incidence among the male gender, which has been the trend over the last two decades 
Table 1 Incidence of pancreatic cancer and HDI in Asia-Pacific and Oceania

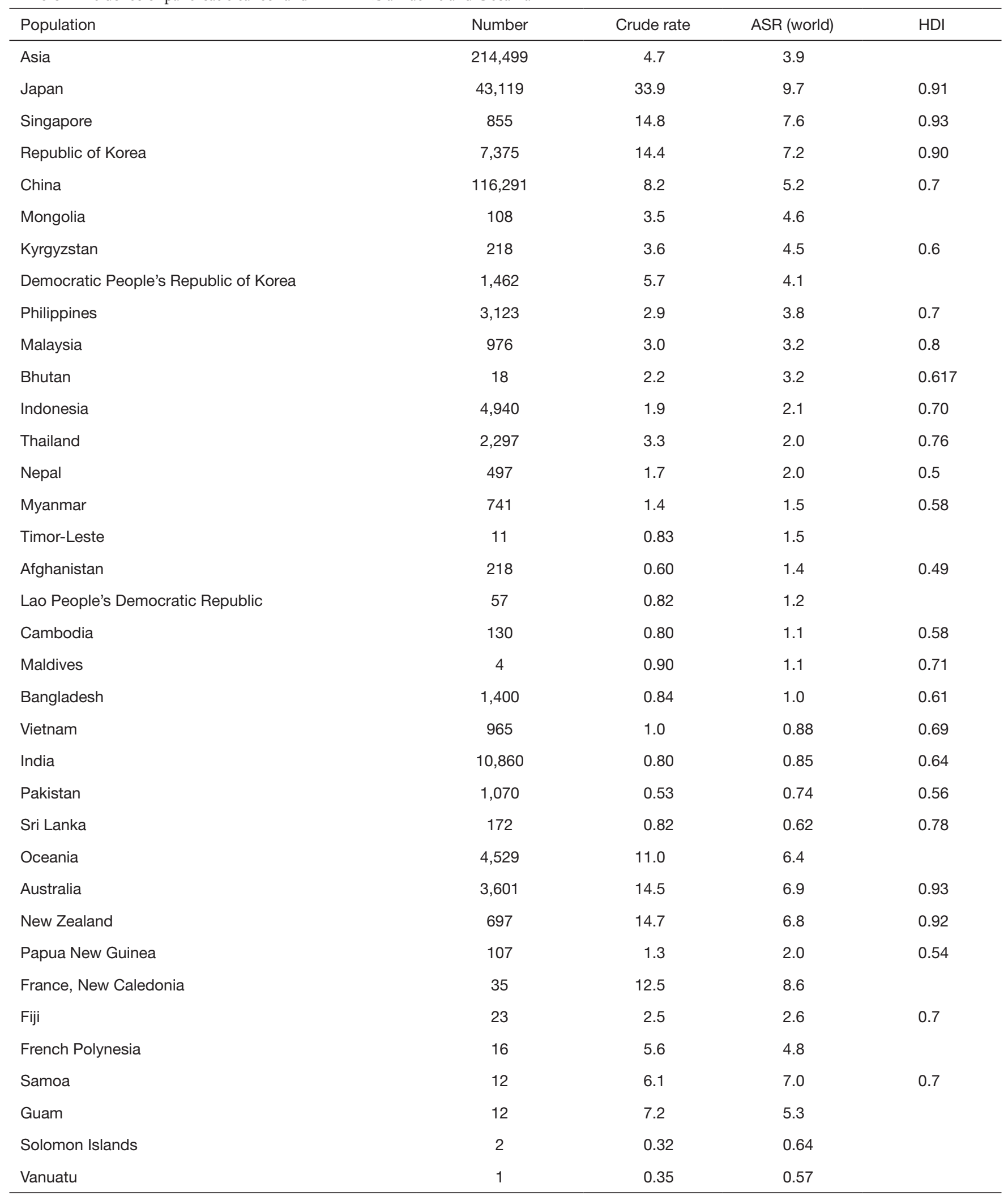

HDI, human development index; ASR, age standardized rate. 


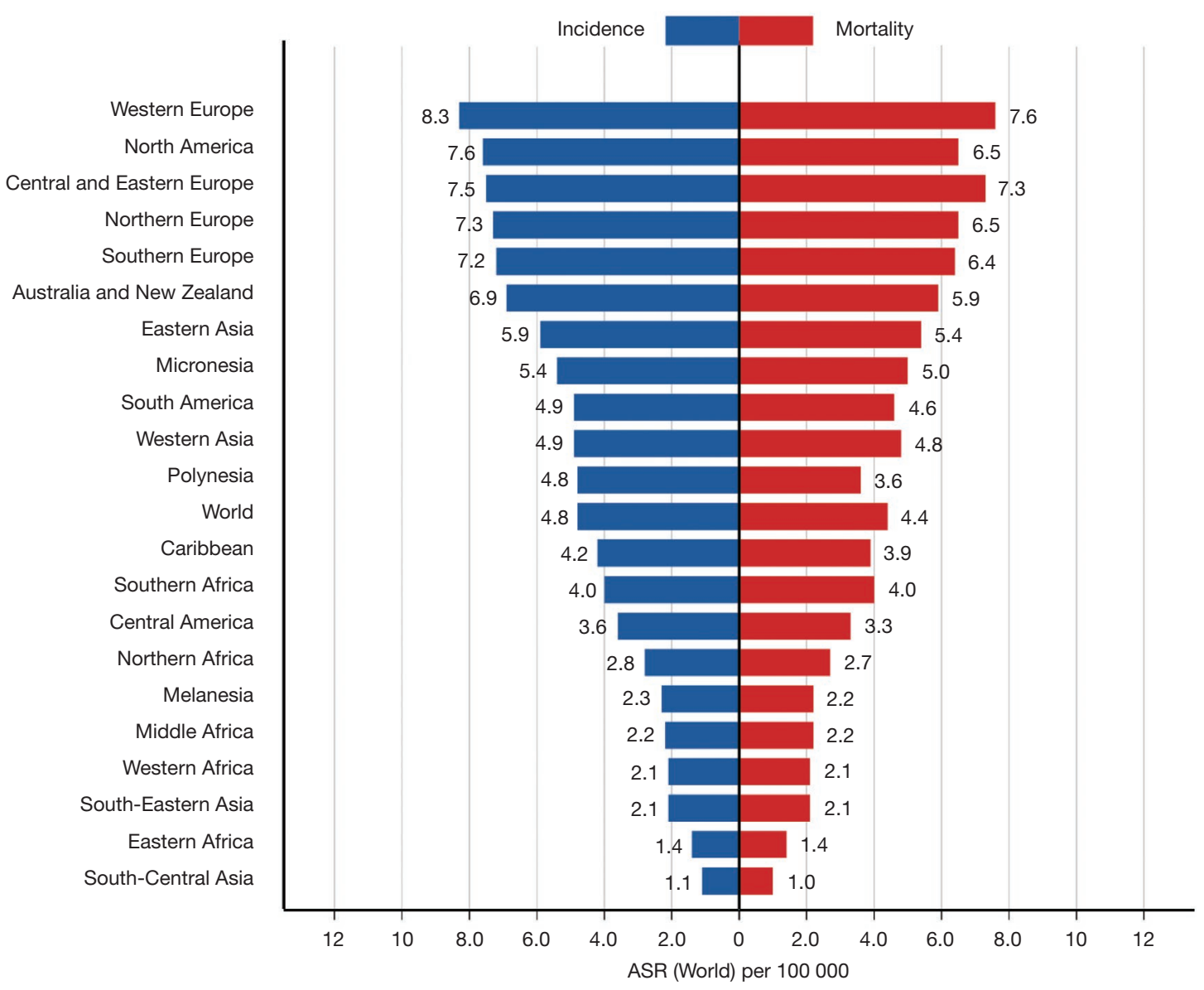

Figure 2 Age standardized (world) incidence and mortality rates of pancreatic cancer.

(Figure 3). This is possibly due to tobacco smoking and alcohol consumption being higher in the male sex leading to chronic pancreatitis which is a risk factor for pancreatic cancer. Diabetic men who are smokers have an elevated risk (8-10) (Figure 3). The prevalence of pancreatic cancer in Asia and Oceania mirrors the pattern in Europe and North America, which have the highest pancreatic cancer disease burden (Table 2).

\section{Results from the Asia-Pacific region}

Asia is the earth's largest and most populated continent. With more than 4.5 billion people, it is home to $60 \%$ of the population of the world. The Asia-Pacific region includes East Asia, South Asia, Southeast Asia, and Oceania.
It has multiple races and ethnicities with a high population density. There is variation in the pancreatic cancer incidence and mortality in the various countries in the continent. There are gaps in the published data as the registries in the Asia-Pacific regions are not comprehensive. In China, the present cancer registries are estimated to cover less than $15 \%$ of the country's population $(11,12)$.

China, followed by Japan and India, accounts for the majority of the new cases of pancreatic cancer (Figure 4). However, when adjusted for population and age standardized rates (ASRs), the incidence, prevalence and mortality in Japan and other advanced economies in the region with high HDI like Singapore and South Korea do worse than China (Table 3).

In Japan, the crude incidence rate is $33.9 / 100,000$, while 


\section{Age standardized (World) incidence rates, pancreas, by sex}

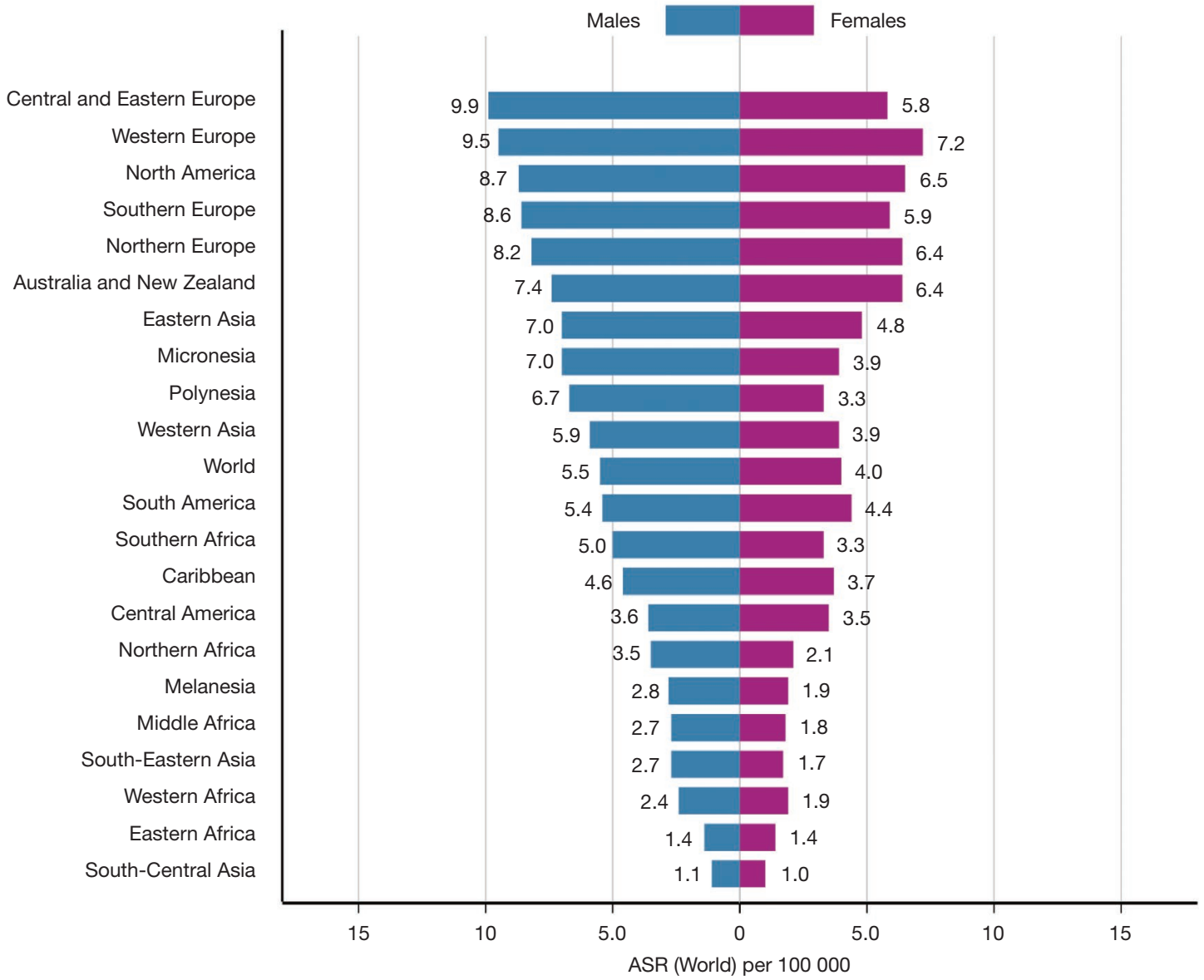

Figure 3 Age standardized incidence rates of pancreatic cancer by sex.

Table 2 Estimated number of prevalent cases in all continents

\begin{tabular}{lcc}
\hline Population & 5-year & Proportions* $^{*}$ \\
\hline Asia & 131,460 & 2.9 \\
Europe & 79,268 & 10.7 \\
North America & 36,030 & 9.9 \\
Latin America and & 21,542 & 3.3 \\
Caribbean & & \\
Africa & 11,484 & 0.89 \\
Oceania & 2,790 & 6.8 \\
\hline
\end{tabular}

*, Proportions per 100,000. Source: GLOBOCAN, 2018. the prevalence is $18.2 \%$ and mortality is $29.4 / 100,000$, compared to the Asian average crude incidence rate of $4.7 / 100,000$ and mortality of 4.4/100,000. China, being the most populous country in Asia, has a crude incidence rate of $8.2 / 100,000$ and mortality of $7.8 / 100,000$.

Oceania, which accounts for 40 million people, follows a similar theme for distribution of pancreatic cancer as countries with a high HDI in the western world, having worse incidence, prevalence and mortality rates. The overall crude incidence rate and mortality for Oceania is $11 / 100,000$ and $9 / 100,000$, respectively. Australia and New Zealand having similar crude incidence rate of 


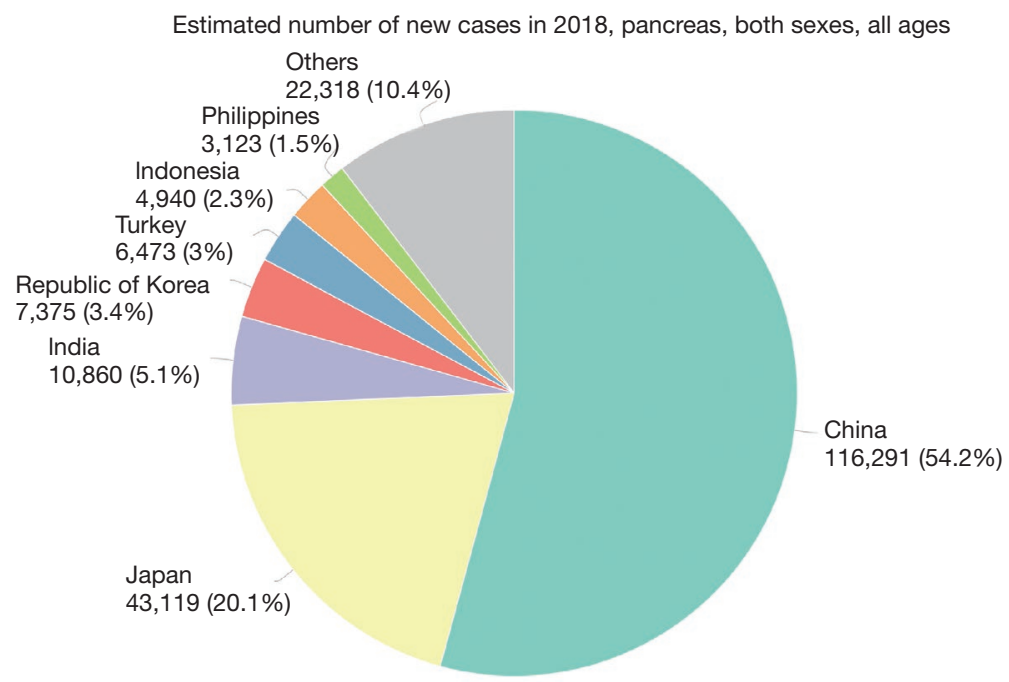

$$
\begin{aligned}
& \text { Data source: Globocan } 2018 \\
& \text { Graph production: Global Cancer } \\
& \text { Observatory (http://gco.iarc.fr) }
\end{aligned}
$$

Total: 214,499

Figure 4 Proportion of new cases of pancreatic cancer in Asian countries.

14.5/100,000. The mortality rates in Australia and New Zealand are 14.7/100,000 and 12.8/100,000 respectively (Table 4).

\section{Etiology and risk factors of pancreatic cancer}

The incidence and mortality of pancreatic cancer has increased over the last five decades in the developed economies (13). Improvement in access to health care and adoption of imaging technologies like magnetic resonance cholangiopancreatography (MRCP) and endoscopic ultrasound have removed hurdles in diagnosing pancreatic cancer and aided preoperative decision making. Unfortunately, there are no early symptoms or signs and no cost-effective screening tools for an early diagnosis. This may partly explain the rise in incidence of pancreatic cancer, without a decline in the mortality. Therefore, a good understanding of the risk factors contributing to the development of pancreatic cancer is warranted.

The etiology and risk factors of pancreatic cancer have been a focus of numerous studies. The risk factors for pancreatic cancer can be broadly classified based on the relative risks (RRs) (14).

The $R R$ of pancreatic cancer is highest $(R R>2)$ for those with a history of chronic pancreatitis, idiopathic thrombosis and those with germ line mutations.

Factors like tobacco smoking, diabetes mellitus, family history of pancreatic cancer, and metabolic syndrome confer a moderate risk (RR: 1.5-1.9). The rising prevalence of diabetics coupled with a rise in smoking has been an important factor contributing to the rise of pancreatic cancer in the Asia-Pacific population (8). Obesity, hepatitis B infection, heavy alcohol intake, helicobacter pylori infection, red and processed meat consumption. and history of cholecystectomy and gastrectomy fall in the category of low risk (RR: 1.1-1.4) $(15,16)$.

Conversely, allergy, metformin use for diabetes, high fresh fruit and vegetable consumption, and occupational physical activity seem to confer protection against pancreatic cancer.

\section{Hereditary and genetic factors}

Ethnicity and genetic factors seem to play a strong role in pancreatic cancer. In the U.S., Asian-Americans and Pacific Islanders seem to have a lower incidence of pancreatic cancer and better survival compared to African Americans and Caucasians (17). Differential expression of Kras and p53 in the Chinese, Japanese and Caucasian population may contribute to the difference in aggressiveness of the tumor. 
Table 3 Prevalence of pancreatic cancer in Asia-Pacific and Oceania

\begin{tabular}{|c|c|c|}
\hline Population & 5-year & Proportions* \\
\hline Japan & 23,134 & 18.2 \\
\hline Singapore & 544 & 9.4 \\
\hline Republic of Korea & 4,756 & 9.3 \\
\hline China & 70,154 & 4.9 \\
\hline $\begin{array}{l}\text { Democratic People's Republic } \\
\text { of Korea }\end{array}$ & 923 & 3.6 \\
\hline Thailand & 1,529 & 2.2 \\
\hline Philippines & 2,136 & 2.0 \\
\hline Malaysia & 642 & 2.0 \\
\hline Bhutan & 12 & 1.5 \\
\hline Indonesia & 3,430 & 1.3 \\
\hline Nepal & 365 & 1.2 \\
\hline Myanmar & 524 & 0.97 \\
\hline Viet Nam & 781 & 0.81 \\
\hline $\begin{array}{l}\text { Lao People's Democratic } \\
\text { Republic }\end{array}$ & 48 & 0.69 \\
\hline Bangladesh & 1,060 & 0.64 \\
\hline India & 8,453 & 0.62 \\
\hline Sri Lanka & 128 & 0.61 \\
\hline Cambodia & 97 & 0.60 \\
\hline Timor-Leste & 8 & 0.60 \\
\hline Afghanistan & 159 & 0.44 \\
\hline Pakistan & 843 & 0.42 \\
\hline Australia & 2,234 & 9.0 \\
\hline New Zealand & 414 & 8.7 \\
\hline Papua New Guinea & 77 & 0.91 \\
\hline France, New Caledonia & 23 & 8.2 \\
\hline Fiji & 14 & 1.5 \\
\hline French Polynesia & 10 & 3.5 \\
\hline Samoa & 8 & 4.0 \\
\hline Guam & 7 & 4.2 \\
\hline Solomon Islands & 2 & 0.32 \\
\hline Vanuatu & 1 & 0.35 \\
\hline
\end{tabular}

*, Proportions per 100,000.
However, dietary habits, smoking and environmental exposure may be the confounding factors (18).

Ten percent of pancreatic cancers are thought to be due to genes passed along families and germ line mutations. Peutz-Jeghers syndrome, melanoma pancreatic-cancer syndrome or familial atypical multiple mole melanoma, hereditary breast-ovarian cancer are strongly associated with development of pancreatic cancer. Lynch syndrome and familial adenomatous polyposis have association to development of pancreatic cancer to a lesser extent (19). The genetic syndromes associated with pancreatic cancer are shown in Table 5 .

The risk is elevated two-fold if two or more first degree relatives have a history of pancreatic cancer, even after controlling for smoking. However the RRs vary across studies (20). Considering the RRs across various studies, screening people with a family history of pancreatic cancer may be a cost-effective intervention. Unfortunately, the available data on genetic syndromes and familial association in the Asia-Pacific population is limited with some data coming from Japan (21). Targeted screening of individuals with a strong family history or a germline mutation is worth implementing.

\section{Smoking}

Numerous case control and cohort studies, along with meta-analysis of studies across a varied population, have concluded a strong association between smoking and the risk of developing pancreatic cancer. The RR of developing pancreatic cancer among smokers can be as high as 1.7 (22). Matsuo and colleagues demonstrated the association of smoking with the risk of developing pancreatic cancer in the Japanese population (23). Pooled analysis in the Asia-Pacific population has shown that current smokers had a $60 \%$ increased risk of developing pancreatic cancer, even after other factors were controlled $(8,24,25)$. A meta-analysis has demonstrated that the risk of developing pancreatic cancer is independent of the number of pack years of smoking and is not dose dependent (26). There is also an increased mortality due to pancreatic cancer among smokers and former smokers compared to non-smokers. This effect was observed in the Western as well as Asia-Pacific populations $(9,27,28)$, and an association was found to be independent of alcohol use, body mass index (BMI), and history of 
Table 4 Mortality from pancreatic cancer in Asia-Pacific and Oceania

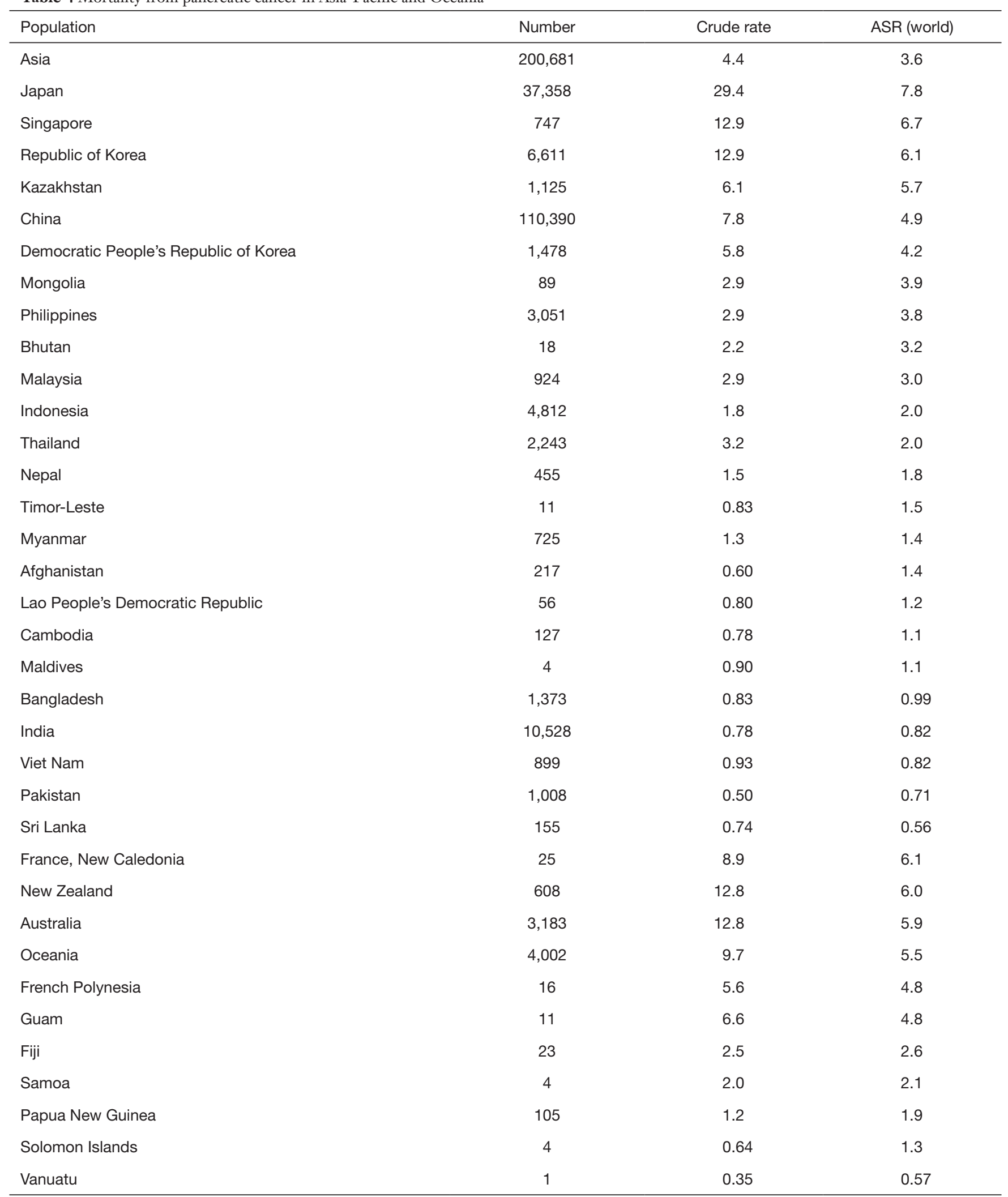

ASR, age standardized rate. 
Table 5 The genetic syndromes associated with pancreatic cancer

\begin{tabular}{lr}
\hline Syndrome & Associated genes \\
\hline Peutz-Jeghers syndrome & STK11 \\
Hereditary pancreatitis & $P R S S 1$ \\
Familial multiple mole melanoma syndrome/ melanoma pancreatic-cancer syndrome & $P 16$, CDKN2A \\
Hereditary breast and ovarian cancer & BRCA 1 and BRCA 2 \\
Ataxic telangiectasia & ATM \\
Von-Hippel-Lindau syndrome & VHL \\
Lynch syndrome & MLH1, MSH2, MSH6 \\
Hereditary pancreatitis & $P R S S 1$, SPINK1 \\
Li-Fraumeni syndrome & P53 \\
\hline
\end{tabular}

diabetes (29). In China, the population attributable fraction for smoking is $6 \%$ but a wide difference is seen between genders: male $35 \%$ and females $2 \%(8,30)$. With increase in the rates of smoking among the younger age group, especially in males in China and India, one can expect a rise in the incidence of pancreatic cancer in this cohort over the next decade $(31,32)$.

\section{Alcohol}

Alcohol consumption elevates the risk of developing pancreatitis, which has a strong association with the development of pancreatic cancer. A recent meta-analysis has demonstrated the dose related association of alcohol with pancreatic cancer. Low to moderate amount of alcohol consumption did not confer an increased risk of developing pancreatic cancer, but consumption of high levels of alcohol (>15 g/day) appears to be a strong risk factor, especially in men. Surprisingly, pancreatic cancer risk was not elevated in women, irrespective of the alcohol dose. This may be due to fewer women being heavy drinkers (33).

\section{Obesity}

The strong association between obesity and cancer is evident through prior data. Pancreatic cancer is no exception (34). Obesity is associated with increased risk of various cancers which is driven by the following mechanisms:

* Chronic low-level inflammation and DNA damage;

* Increased production of estrogen in the fat tissue;
* Increased levels of insulin and IGF-1;

* Adipokines which may have a growth promoting effect;

Direct and indirect effects on other cell growth regulators, including mammalian target of rapamycin (mTOR) and AMP-activated protein kinase;

A recent animal study has demonstrated that obesity promotes pancreatic cancer by altering the nitrogen metabolism (35).

Being overweight and being obese in early adulthood independently increases the risk of pancreatic cancer compared to people with normal body weight, as demonstrated by pooled cohort and meta-analysis (14, 36-39). Central obesity increased pancreatic cancer risk in the Asia-Pacific population in one study (8).

\section{Diet}

The association of diet and pancreatic cancer has been a subject of multiple epidemiological studies. Consumption of red and processed meat ( $>50 \mathrm{~g} /$ day) is associated with at least a $20 \%$ increase in risk of pancreatic cancer $(40,41)$. People consume more meat as countries get richer (42). Middle income countries in Asia may see a spike in pancreatic cancer if this trend continues. Daily consumption of fresh fruit and vegetable is known to lead to at least a $30 \%$ reduction in the risk of cancer (43). The protective effects of coffee and tea against pancreatic cancer could not be conclusively demonstrated (44). Despite all the data, the strength of association between diet and pancreatic cancer is only moderate, at best. 


\section{Chronic pancreatitis, diabetes and pancreatic cancer}

Chronic pancreatitis is strongly associated with the development of pancreatic cancer. At least $5 \%$ of patients with chronic pancreatitis eventually develop pancreatic cancer, while there is a 50 -fold increase in pancreatic cancer in patients with hereditary and tropical pancreatitis. The repeated glandular damage due to inflammation is postulated to be the cause for the development of cancer (45).

Diabetes mellitus is extensively studied as a risk factor for pancreatic cancer. Various meta-analysis have demonstrated a strong link between the two, with a greater than $50 \%$ risk of pancreatic cancer in people with long term diabetes associated with obesity and poor glycemic control. The postulated mechanisms are the tumorigenic effect of hyperglycemia and growth promoting effects of hyperinsulinemia. In patients with diabetes for greater than 10 years, the RR (95\% CI) of PC was 1.50 (1.28-1.75) (46). With a large population of diabetics and undiagnosed diabetics living in South Asia, coupled with increasing obesity, an uptick in cases of pancreatic cancer should be expected (47). A recent meta-analysis in China has reported a $>$ two-fold risk of pancreatic cancer in people who have had diabetes for less than 2 years (48). Metformin when used to manage diabetes is shown to decrease the risk of developing pancreatic cancer.

\section{Prior surgery and pancreatic cancer}

Cholecystectomy is one of the most commonly performed general surgical procedures, worldwide. Meta-analyses have demonstrated that it confers a greater than $20 \%$ excess risk of developing pancreatic cancer [standardized rate ratio (SRR): $1.23 ; 95 \%$ CI: $1.12-1.35]$. This may be due to increase in the secondary bile salt concentration postsurgery as well as an increase in the cholecystokinin levels which may promote the growth of pancreatic cancer (15).

Gastrectomy may increase the risk of developing pancreatic cancer by $50 \%$, especially when the procedure was performed within 2 years of the pancreatic cancer diagnosis. The postulated mechanism is increased $H$. pylori colonization and $\mathrm{N}$-nitroso amine compound formation, due to the reduced gastric acid production secondary to the procedure (49).

\section{Policies and interventions}

Australia, Japan and China are predicted to see large increases in the pancreatic cancer incidence burden between now and 2040 with Australia slated to have an increase of more than $60 \%$ from the current levels (13).

Screening for pancreatic cancer by imaging or blood tests may not be a cost-effective option in the general population due to the low lifetime risk of developing pancreatic cancer; when there is a strong family history of cancer or a germline mutation that is identified, there is value in screening. The risk of overtreatment with screening as well as costs, needs to be considered as well in low resource setting. There is no consensus on screening for pancreatic cancer at this time.

The presence of modifiable risk factors makes policy and interventions feasible in preventing pancreatic cancer. Smoking is a risk factor that is implicated as an agent in several cancers. Unlike lung cancer, where a single factor like smoking is strong implicated, causation of pancreatic cancer is multifactorial. Government policy that is focused on education, financial incentives for a healthy lifestyle, taxation of tobacco products at a reasonable level and adequate support to people who are motivated to quit smoking is likely to help in reducing the risks, although a total elimination may not be possible. With vaping gaining popularity in the younger age group and people trying to quit conventional cigarette smoking, the association between vaping and pancreatic cancer needs to be studied (50,51).

The data on Helicobacter pylori infection as a possible risk factor for pancreatic cancer is not clear (52). Therapy to eradicate infection through antibiotics is likely to eliminate this risk factor and may be useful when the patients undergo an upper gastrointestinal endoscopy for other reasons.

Diet, exercise and awareness about obesity as a risk factor for cancer has the potential to effect change globally, more than any other intervention. Limiting red meat and animal based protein, limiting processed foods and sugar intake by decreasing consumption of carbonated beverages can decrease the prevalence of obesity (53). Obesity which was primarily a problem with developed economies is now a concern in developing middle income countries. With the economic progress in China and India lifting people out of poverty at unprecedented rates, incidence and prevalence of obesity and cancer is likely to follow a similar trajectory.

A concerted effort by governments to put policies in place to decrease or eliminate risk factors will have a 
meaningful, cost-effective but high impact in the fight against pancreatic cancer. Advances in medical technology and delivering care for patients in high volume centers in these countries will assure good outcome in patients who are able to receive definitive care for pancreatic cancer.

\section{Acknowledgments}

Funding: None.

\section{Footnote}

Provenance and Peer Review: This article was commissioned by the editorial office, Journal of Gastrointestinal Oncology for the series "Global GI Malignancies". The article has undergone external peer review.

Conflicts of Interest: Both authors have completed the ICMJE uniform disclosure form (available at http:// dx.doi.org/10.21037/jgo-20-118). The series "Global GI Malignancies" was commissioned by the editorial office without any funding or sponsorship. QC served as the unpaid Guest Editor of the series. The authors have no other conflicts of interest to declare.

Ethical Statement: The authors are accountable for all aspects of the work in ensuring that questions related to the accuracy or integrity of any part of the work are appropriately investigated and resolved.

Open Access Statement: This is an Open Access article distributed in accordance with the Creative Commons Attribution-NonCommercial-NoDerivs 4.0 International License (CC BY-NC-ND 4.0), which permits the noncommercial replication and distribution of the article with the strict proviso that no changes or edits are made and the original work is properly cited (including links to both the formal publication through the relevant DOI and the license). See: https://creativecommons.org/licenses/by-nc-nd/4.0/.

\section{References}

1. Bray F, Ferlay J, Soerjomataram I, et al. Global cancer statistics 2018: GLOBOCAN estimates of incidence and mortality worldwide for 36 cancers in 185 countries. CA Cancer J Clin 2018;68:394-424.

2. Wong MCS, Jiang JY, Liang M, et al. Global temporal patterns of pancreatic cancer and association with socioeconomic development. Sci Rep 2017;7:3165.

3. Veisani Y, Jenabi E, Khazaei S, et al. Global incidence and mortality rates in pancreatic cancer and the association with the Human Development Index: decomposition approach. Public Health 2018;156:87-91.

4. Haugvik SP, Hedenström P, Korsæth E, et al. Diabetes, smoking, alcohol use, and family history of cancer as risk factors for pancreatic neuroendocrine tumors: a systematic review and meta-analysis. Neuroendocrinology 2015;101:133-42.

5. Xiao AY, Tan ML, Wu LM, et al. Global incidence and mortality of pancreatic diseases: a systematic review, metaanalysis, and meta-regression of population-based cohort studies. Lancet Gastroenterol Hepatol 2016;1:45-55.

6. Ilic M, Ilic I. Epidemiology of pancreatic cancer. World J Gastroenterol 2016;22:9694-705.

7. Howlader N, Noone AM, Krapcho M, et al. SEER Cancer Statistics Review, 1975-2014, National Cancer Institute. Bethesda, MD, https://seer.cancer.gov/csr/1975_2014/, based on November 2016 SEER data submission, posted to the SEER web site, April 2017.

8. Ansary-Moghaddam A, Huxley R, Barzi F, et al. The effect of modifiable risk factors on pancreatic cancer mortality in populations of the Asia-Pacific region. Cancer Epidemiol Biomarkers Prev 2006;15:2435-40.

9. Pourhoseingholi MA, Ashtari S, Hajizadeh N, et al. Systematic review of pancreatic cancer epidemiology in Asia-Pacific Region: major patterns in GLOBACON 2012. Gastroenterol Hepatol Bed Bench 2017;10:245-57.

10. Yadav D, Lowenfels AB. The epidemiology of pancreatitis and pancreatic cancer. Gastroenterology 2013;144:1252-61.

11. Siegel R, Ma J, Zou Z, et al. Cancer statistics, 2014. CA Cancer J Clin 2014;64:9-29.

12. He J, Chen W. Chinese cancer registry annual report 2012. Beijing: Press of Military Medical Sciences, 2012:68-71.

13. Maisonneuve P. Epidemiology and burden of pancreatic cancer. Presse Med 2019;48:e113-23.

14. Maisonneuve P, Lowenfels AB. Risk factors for pancreatic cancer: a summary review of meta-analytical studies. Int J Epidemiol 2015;44:186-98.

15. Lin G, Zeng Z, Wang X, et al. Cholecystectomy and risk of pancreatic cancer: a meta-analysis of observational studies. Cancer Causes Control 2012;23:59-67.

16. Gong Y, Zhou Q, Zhou Y, et al. Gastrectomy and risk of pancreatic cancer: systematic review and meta- 
analysis of observational studies. Cancer Causes Control 2012;23:1279-88.

17. Longnecker DS, Karagas MR, Tosteson TD, et al. Racial differences in pancreatic cancer: comparison of survival and histologic types of pancreatic carcinoma in Asians, blacks, and whites in the United States. Pancreas 2000;21:338-43.

18. Dong M, Nio Y, Tamura K, et al. Ki-ras point mutation and $\mathrm{p} 53$ expression in human pancreatic cancer: a comparative study among Chinese, Japanese, and Western patients. Cancer Epidemiol Biomarkers Prev 2000;9:279-84.

19. Ghiorzo P. Genetic predisposition to pancreatic cancer. World J Gastroenterol 2014;20:10778-89.

20. Permuth-Wey J, Egan KM. Family history is a significant risk factor for pancreatic cancer: results from a systematic review and meta-analysis. Fam Cancer 2009;8:109-17.

21. Masamune A, Kume K, Shimosegawa T. Differential roles of the SPINK1 gene mutations in alcoholic and nonalcoholic chronic pancreatitis. J Gastroenterol 2007;42 Suppl 17:135-40.

22. Iodice S, Gandini S, Maisonneuve P, et al. Tobacco and the risk of pancreatic cancer: a review and meta-analysis. Langenbecks Arch Surg 2008;393:535-45.

23. Matsuo K, Ito H, Wakai K, et al. Cigarette smoking and pancreas cancer risk: an evaluation based on a systematic review of epidemiologic evidence in the Japanese population. Jpn J Clin Oncol 2011;41:1292-302.

24. Katanoda K, Marugame T, Saika K, et al. Population attributable fraction of mortality associated with tobacco smoking in Japan: a pooled analysis of three large-scale cohort studies. J Epidemiol 2008;18:251-64.

25. Lynch SM, Vrieling A, Lubin JH, et al. Cigarette smoking and pancreatic cancer: a pooled analysis from the pancreatic cancer cohort consortium. Am J Epidemiol 2009; 170:403-13.

26. Zou L, Zhong R, Shen N, et al. Non-linear doseresponse relationship between cigarette smoking and pancreatic cancer risk: evidence from a meta-analysis of 42 observational studies. Eur J Cancer 2014;50:193-203.

27. Islami F, Chen W, Yu XQ, et al. Cancer deaths and cases attributable to lifestyle factors and infections in China, 2013. Ann Oncol 2017;28:2567-74.

28. Wilson LF, Antonsson A, Green AC, et al. How many cancer cases and deaths are potentially preventable? Estimates for Australia in 2013. Int J Cancer 2018;142:691-701.

29. Ben QW, Liu J, Sun YW, et al. Cigarette smoking and mortality in patients with pancreatic cancer: a systematic review and meta-analysis. Pancreas 2019;48:985-95.

30. Parkin DM. 1. The fraction of cancer attributable to lifestyle and environmental factors in the UK in 2010. Br J Cancer 2011;105 Suppl 2:S2-5.

31. Mishra S, Joseph RA, Gupta PC, et al. Trends in bidi and cigarette smoking in India from 1998 to 2015, by age, gender and education. BMJ Glob Health 2016;1:e00005.

32. Li S, Meng L, Chiolero A, et al. Trends in smoking prevalence and attributable mortality in China, 1991-2011. Prev Med 2016;93:82-7.

33. Wang YT, Gou YW, Jin WW, et al. Association between alcohol intake and the risk of pancreatic cancer: a doseresponse meta-analysis of cohort studies. BMC Cancer 2016;16:212.

34. Renehan AG, Tyson M, Egger M, et al. Body-mass index and incidence of cancer: a systematic review and metaanalysis of prospective observational studies. Lancet 2008;371:569-78.

35. Zaytouni T, Tsai PY, Hitchcock DS, et al. Critical role for arginase 2 in obesity-associated pancreatic cancer. Nat Commun 2017;8:242.

36. Arslan AA, Helzlsouer KJ, Kooperberg C, et al. Anthropometric measures, body mass index, and pancreatic cancer: a pooled analysis from the Pancreatic Cancer Cohort Consortium (PanScan). Arch Intern Med 2010;170:791-802.

37. Genkinger JM, Spiegelman D, Anderson KE, et al. A pooled analysis of 14 cohort studies of anthropometric factors and pancreatic cancer risk. Int J Cancer 2011;129:1708-17.

38. Jiao L, Berrington de Gonzalez A, Hartge P, et al. Body mass index, effect modifiers, and risk of pancreatic cancer: a pooled study of seven prospective cohorts. Cancer Causes Control 2010;21:1305-14.

39. GBD 2017 Pancreatic Cancer Collaborators. The global, regional, and national burden of pancreatic cancer and its attributable risk factors in 195 countries and territories, 1990-2017: a systematic analysis for the Global Burden of Disease Study 2017. Lancet Gastroenterol Hepatol 2019;4:934-47.

40. Paluszkiewicz P, Smolińska K, Dębińska I, et al. Main dietary compounds and pancreatic cancer risk. The quantitative analysis of case-control and cohort studies. Cancer Epidemiol 2012;36:60-7.

41. Larsson SC, Wolk A. Red and processed meat consumption and risk of pancreatic cancer: meta-analysis of prospective studies. Br J Cancer 2012;106:603-7.

42. Ritchie H, Roser M. Meat and dairy production. 
Our World in Data 2017. Available online: https:// ourworldindata.org/meat-production

43. Koushik A, Spiegelman D, Albanes D, et al. Intake of fruits and vegetables and risk of pancreatic cancer in a pooled analysis of 14 cohort studies. Am J Epidemiol 2012;176:373-86.

44. Genkinger JM, Li R, Spiegelman D, et al. Coffee, tea, and sugar-sweetened carbonated soft drink intake and pancreatic cancer risk: a pooled analysis of 14 cohort studies. Cancer Epidemiol Biomarkers Prev 2012;21:305-18.

45. Raimondi S, Lowenfels AB, Morselli-Labate AM, et al. Pancreatic cancer in chronic pancreatitis; aetiology, incidence, and early detection. Best Pract Res Clin Gastroenterol 2010;24:349-58.

46. Song S, Wang B, Zhang X, et al. Long-term diabetes mellitus is associated with an increased risk of pancreatic cancer: a meta-analysis. PLoS One 2015;10:e0134321.

47. Cho NH, Shaw JE, Karuranga S, et al. IDF Diabetes Atlas: global estimates of diabetes prevalence for 2017

Cite this article as: Ranganath $\mathrm{R}$, Chu Q. Global trends in pancreas cancer among Asia-Pacific population. J Gastrointest Oncol 202 1;12(Suppl 2):S374-S386. doi: 10.21037/jgo-20-118 and projections for 2045. Diabetes Res Clin Pract 2018;138:271-81.

48. Zhang JJ, Jia JP, Shao Q, et al. Diabetes mellitus and risk of pancreatic cancer in China: A meta-analysis based on 26 case-control studies. Prim Care Diabetes 2019;13:276-82.

49. Bosetti C, Lucenteforte E, Bracci PM, et al. Ulcer, gastric surgery and pancreatic cancer risk: an analysis from the International Pancreatic Cancer Case-Control Consortium (PanC4). Ann Oncol 2013;24:2903-10.

50. Dawkins L, Turner J, Roberts A, et al. 'Vaping' profiles and preferences: an online survey of electronic cigarette users. Addiction 2013;108:1115-25.

51. Gostin LO, Glasner AY. E-cigarettes, vaping, and youth. JAMA 2014;312:595-6.

52. Schulte A, Pandeya N, Fawcett J, et al. Association between Helicobacter pylori and pancreatic cancer risk: a meta-analysis. Cancer Causes Control 2015;26:1027-35.

53. Poti JM, Braga B, Qin B. Ultra-processed food intake and obesity: what really matters for health-processing or nutrient content? Curr Obes Rep 2017;6:420-31. 